\title{
Ayanis Kalesi Podyumlu Salon Taş ve Metal Buluntuları
}

\author{
Stone and Metal Finds Encountered in the Podium Hall of Ayanis Castle
}

\author{
Ayșegül AKIN ARAS 1 \\ Oğuz ARAS 2 \\ Mehmet Ali ÖZDEMIR ${ }^{3}$
}

\author{
Araştırma Makalesi/ Research Article \\ Geliş Tarihi / Received: 04.03.2121 \\ Kabul Tarihi / Accepted: 19.04.2021 \\ Doi: 10.48146/odusobiad.891194
}

Atıf / Citation: Akın Aras, M., Aras, O. ve Özdemir, M. A., (2021). "Ayanis Kalesi Podyumlu Salon Taş ve Metal Buluntularl” ODUSOBİAD, 11(2), 365-376, doi: 10.48146/odusobiad.891194.

\section{Öz}

MÖ 9. yüzyıl ortalarında Dağlık Doğu Anadolu ve yakın civarındaki topraklarda egemen politik güç olarak karşımıza Urartu Devleti çıkar. Batıda Fırat nehri, güneydoğuda Urmiye Gölü, kuzeyde Erzurum-Kars platosu ve kuzeydoğuda Sevan Gölü'ne değin geniş bir coğrafyaya hükmetmeyi başarmışlardır. Urartu kralları, devletin temellerini Van Gölü çevresinde atmıș ve kısa sürede Tușpa'yı başkent ilan etmişlerdir. Urartu Krallığı en parlak dönemini Argiști oğlu Rusa döneminde yaşamıştır. Argişti oğlu Rusa egemenlik yıllarında inşa ettirdiği beş büyük kaleden biri Ayanis Kalesi'dir. 1989 yılından itibaren kesintisiz olarak devam eden çalıșmalar neticesinde Ayanis Kalesi'nde Urartu kültürüne ışık tutan birçok mimari yapı ve buluntu grubu ortaya çıkarılmıştır. Ayanis Kalesi son dönem kazılarında Urartu kültüründe bir benzerine rastlamadığımız mimari yapı ile karşılaşırız. Podyumlu Salon olarak nitelendirilen bu alanın henüz işlevine dair öneriler devam etmekte olduğundan yapının net olarak işlevi bilinmemektedir. Bu makalede Podyumlu Salonun işlevine dair önerilerden ziyade, salondan ele geçen taş ve metal buluntuların genel bir değerlendirmesi yapılacaktır.

Anahtar Kelimeler: Arkeoloji, Urartu, Ayanis, Podyumlu Salon, Buluntu.

\begin{abstract}
In the mid-9th century $B C$, the Urartian State emerged as the dominant political power in the mountainous Eastern Anatolia and its nearby lands. They ruled over a wide geographic area from the Euphrates River in the west to Lake Urmiye in the southeast, from Erzurum-Kars plateau in the north to Lake Sevan in the northeast. The Urartian kings laid the foundations of the state around Lake Van and declared Tuşpa as their capital in a short time. Ayanis Castle is one of the five big castles built by Argiști's son Rusa during his reign. In the recent excavations of Ayanis Castle, an architectural structure that we have not seen in the Urartian culture before is noteworthy. Suggestions regarding the function of this area, which is described as a Podium Hall, are still in progress. In this article, a general evaluation of stone and metal finds unearthed in the Podium Hall will be presented.
\end{abstract}

Keywords: Archeology, Urartian, Ayanis, Podium Hall, Find.

\section{Giriş}

Dağlık Doğu Anadolu Yaylasının görkemli krallı̆̆ı olarak bilinen Urartu, MÖ I. binyılda merkezini Van Gölü Havzası'nın oluşturduğu coğrafyada ortaya çıkmış, ilerleyen süreçlerde Aras Havzası ve İran Azerbaycanı'na kadar yayılım göstermiş önemli bir krallıktır (Çilingiroğlu, 1997: 4-8; Salvini, 2006:

${ }^{1}$ Sorumlu Yazar, Arş. Gör., Atatürk Üniversitesi Edebiyat Fakültesi Arkeoloji Bölümü, Erzurum, e-mail: aysglakin@gmail.com, ORCID ID: 0000-0002-6540-7560 05078714120

${ }^{2}$ Arş. Gör., Atatürk Üniversitesi Edebiyat Fakültesi Arkeoloji Bölümü, Erzurum, e-mail: ogzars@gmail.com, ORCID ID: 00000001-9291-1597

${ }^{3}$ Dr. Öğrencisi, Atatürk Üniversitesi Edebiyat Fakültesi Arkeoloji Bölümü, Erzurum, e-mail: arkeomali@gmail.com, ORCID ID: 0000-0003-2740-7743. 
24-25). Yüksek dağlarla çevrili olan bu coğrafyada zorlu ve sert iklim koşulları ile baş etmeyi başarabilmiş bu toplumun, Doğu Anadolu'nun tarihsel sürecinde köklü değişiklikler yarattığı ve bölgeyi ilk merkezi devlet yapılanması ile tanıştırdığı görülür. Yaklaşı iki yüz elli yıl boyunca hüküm süren Urartular, bu merkezi otoriteyi tesis etmek için görkemli kentler ve dış kentler inşa ettirmişlerdir. Bu durumda yine bu coğrafyanın görmüş olduğu bir yenilik olarak karşımıza çıkmıştır.

Yönetim modelinden kentleşmeye, yazıdan sanata kadar birçok alanda yeniliklerin ortaya çıktığı Orta Demir Çağı Doğu Anadolu'su kuşkusuz tek başına bile gelişimin kaynağıdır. Ancak uzun zaman diliminde varlığını koruyan krallığın kendi dönemi içerisinde de bir gelişim çizgisi izlediği ve bu süreçte de en dikkat çekici evrenin, Argişti oğlu Rusa'nın dönemi olduğu gözlenir. Diğer kralların dönemlerine kıyasla politik açıdan refahın sağlandığı bir dönem olması ile krallık yükselişe geçmiştir. Yaptığı reformlarla adından söz ettiren bu kralın döneminin tüm ihtişamını inşa ettirdiği kentlerde de görmek mümkündür. Van Havzasında yer alan üç kentin yanı sıra biri İran'da biri de Ermenistan'da olmak üzere toplam beş kenti olduğu kabul görür4 . Şüphesiz ki bu kentlerden en özeli, kralın son kralî projesi olarak bilinen Ayanis'tir. Mimarisinden küçük buluntusuna kadar birbirinden etkileyici birçok unsurun bir araya geldiği bir kent olarak Ayanis, kralın dönemine atfedilen Urartu Rönesansı (Çilingiroğlu, 2007: 73-89) ifadesini de tam olarak yansıtmıștır.

Otuz yıldan fazla bir süredir kazı çalışmalarının devam ettiği kentte, Urartu kültürünü yansıtan birçok ögenin yanı sıra kente özgü birçok eser de ortaya çıkarılmıştır. Sitadel ve Dışkent olarak ayrılan kentte kazı çalışmaları her iki kısımda yürütülmüşse de daha çok sitadel alanına yoğunlaşılmıştır. Bu alandaki çalışmalar sonucunda "Tapınak Alanı, Podyumlu Salon, Domestik Mekânlar, Payeli Salon, Anıtsal Kapı, Doğu ve Batı Depo Odaları, Güney-Kuzey-Doğu ve Batı Sur Duvarları ile dış kentin bir bölümü gün ıșığına çıarılmıştır (Çilingiroğlu ve Işıklı, 2014: 310; Çilingiroğlu ve Salvini, 2001: 15-67) (Görsel 1). Şüphesiz bu yapı grupları içerisinde en dikkati çeken yapılar, Haldi Tapınağı'nı da bünyesinde barındıran Tapınak Alanı ve Urartu mimarisi için ünik bir mimari olan Podyumlu Salon'dur.

\section{Podyumlu Salon}

Bu çalışmanın asıl konusunu oluşturan mekân, bu yapılardan biri olan Podyumlu Salon'dur. Yeni dönem kazıları olarak adlandırılan süreçte, 2014-2019 yılları arasında toplam beş sezon devam eden kazı çalışmalarında mekânın mimarisi tam anlamıyla ortaya çıkarılmıştır. İçerisinde yer alan oniks podyum sebebiyle Podyumlu Salon olarak adlandırılan mekân; dikdörtgen bir plana sahip olup, büyük bir ana oda ve daha küçük arka odadan oluşmaktadır. Salonun merkezini olușturan ana oda, kuzey-güney yönünde $22 \mathrm{~m}$, doğu-batı yönünde ise $8 \mathrm{~m}$ ölçülere sahiptir. Salondan bir kapı ile geçişin sağlandığı arka oda ise, kuzey-güney yönünde 4,5 m, doğu-batı yönünde 8 m ölçülere sahip küçük bir mekândır (Görsel 2). Şimdiye değin kazısı gerçekleştirilen hiçbir Urartu kalesinde benzerine rastlamadığımız sadece Tanrı Haldi'ye ithafen yapılan Ayanis Tapınak cellasından bildiğimiz bezemeli bir podyumun bir benzeri ve daha büyüğü bu salondan ele geçmiştir. Podyumun ölçülebilen genişliği yaklaşık olarak 2,70 x 2,60 m iken yüksekliği $70 \mathrm{~cm}$ 'dir. Bu podyumun sağ kısmında kalan zemine ise, 5 x 10 düzeninde yerleştirilmiş 49 adet oniks blok açığa çıkartılmıştır. Yaklaşık olarak 50 x $50 \mathrm{~cm}$ boyutlarına sahip bu bloklar podyumun yanında gerçekleştirilen bir törene işaret etmektedir. Urartu mimarisinde şimdiye değin görülen tüm mimari yapılardan farklı bir plana sahip olan Podyumlu Salon'un işlevi için birkaç öneri sunulmuş olsa da bu hususa netlik kazandırmak oldukça zordur. Mekânın içerisinde ele geçen küçük buluntular her ne kadar azımsanmayacak boyutlarda olsa da buluntu grupları üzerinden mekân işlevselliğine dair yine sadece önerilerde bulunulabilmiştir.

\footnotetext{
${ }^{4}$ Van Havzası'nda yer alan Toprakkale kentinin kurucusunun Argişti oğlu Rusa olmadığına dair görüşler ortaya atılmışsa da bu hususun henüz netlik kazanmaması nedeniyle bu çalışma içerisinde Argişti oğlu Rusa'nın kentleri arasında değerlendirilmiştir. Ancak şu da eklenmelidir ki Toprakkale hangi kral tarafından inşa ettirilmiş olursa olsun içerisinde barındırdığı birçok öge ile Argişti oğlu Rusa dönemini de büyük oranda yansıtmaktadır.
} 
Podyumlu Salon'un işlevine dair temel olarak iki faklı görüş bulunmaktadır. Bu görüşlerin ilki bu mekânın bir taht/kabul salonu olduğudur. Assur mimarisinden bildiğimiz taht odaları şimdiye kadar Urartu kazılarında ortaya çıkmamıştır. Bununla birlikte, Urartu Krallığı'ndaki taht odalarının varlığı her zaman tartışma konusu olmuştur. Toprakkale ve Altıntepe' den ele geçen birkaç metal eser ve bu eserden yola çıkılarak yapılan rekonstrüksiyon denemeleri Urartu Krallı̆̆ı için taht odasını işaret eden tek arkeolojik veri olarak kayıtlara geçmiştir (Barnett, 1950: 43; Seidl, 1994: fig.10; Özgüç, 1969: pl. XXXVI.; Curtis, 2012: 431-438). Asur taht odalarını, genel olarak uzun ince bir mimari düzene sahip ve içerisinde üzerinde tahtın durduğu podyumu barından yapılar olarak tanımlayabiliriz (Cohen-Kangas, 2017: 13). Bu tanım ile Ayanis Kalesi'nde açığa çıkardığımız Podyumlu Salon'un mimari tanımı bire bir örtüşmektedir. Bu mimari benzerliğin yanı sıra arkeolojik verilerde bu alanın taht salonu olabileceğine dair işaretler sunmaktadır. Podyumlu salondan ele geçen 8 adet taş eserin bir tahta ait olması muhtemeldir (Görsel 3). Bir diğer ayrıntı ise, podyumun ön kısmına yakın bir konumda, birbirine simetrik dört adet oval kullanım izi tespit edilmiş olmasıdır. Bu izler her ne kadar tahtın oturak kısmı için küçük olsa da betimlerden bildiğimiz tahtın önünde yer alan ayaklık kısmı için ideal ölçülere ve konuma sahiptir. Bu olgular göz önünde bulundurulduğunda bu alanın taht odası olabileceğini söylemek yanlış olmayacaktır.

Salonun işlevi hakkında bir diğer görüş ise, mekânın tanrıça Arubani ile bağlantılı olabileceğidir. Bu düşüncemizin filizlenmesine sebep olan etmen, yukarıda bahsi geçen arka odanın girişinden ele geçen bullalardır. Bildiğiniz gibi şimdiye değin Urartu'da bildiğimiz kadın isimleri çok sınırlı sayıdaydı. Bu alanda ortaya çıkardığımız tek bir bulla üzerinde üç farklı kadın ismine rastlamış olmamız ve bir bulla üzerinde tanrıça Arubani'ye adanan bir hediyeden bahsetmesi, Podyumlu Salon yeni bir kült alanı mı? sorusunu gündeme getirmiştir. Dikkat çeken başka bir olgu ise, bulla üzerinde olasılıkla bir şölen sahnesine ait olan sahnede, tef çalan kadınlar betimlenmiş olmasıdır. Podyumlu Salon; Susi ile bağlantısı, devasa boyutu, podyumu ve buluntuları ile bizlere yeni bir kült alanının ve taht salonunun varlığını sorgulatmaktadır. Ancak yapının henüz yeni açığa çıkarılmış olması, kazılarının tamamlanmamış olması ve Urartu mimarisinde benzeri olmaması nedenleriyle yapının işlevi ile ilgili olarak net söylemlerde bulunmak zordur.

\section{Taş ve Metal Buluntular}

Yukarıda belirtmiş olduğumuz gibi Podyumlu Salon sadece mimarisi ile değil, buluntu çeşitliliği ile de Urartu kültür envanterine nitelik ve nicelikleri ile özel bir koleksiyon kazandırmıştır. Özellikle metal ve taşa dayalı materyalin yoğunluk oluşturduğu bu alanda ele geçen eserlerin büyük bir bölümü Urartu sanatında ilk kez karşımıza çıkan ünik eserlerdir. Urartu'nun sonuna doğru ilk kez karşımıza çıkan bu örnekler Urartular'ın özellikle tunç ve taş sanatındaki zanaatkârlıklarını da açıkça gösteren kanıtlardır. Bu zanaatkârlıklarının gelişkinliğinde kuşkusuz krallığın bu iki hammaddeye rahatlıkla erişebilir konumda olabilmesinin de payı bulunur. İnce bir iş̧̧ilik ürünü olan bu eserlerde başta din olmak üzere kültüre dair birçok unsuru bir arada görebilmek de mümkündür.

$\mathrm{Bu}$ iki materyale dayalı eser grupları arasından en önemlisini taş eserler oluşturmaktadır. Bu eserlerin tümüne bakıldığında en başta dikkat çeken kusursuz işçilikleri olmuştur. Taşa dayalı anıtsal mimari anlayışı ile dikkatleri üzerine çeken Urartu'nun, özellikle bu dönemde ve bu mekânda ortaya koymuş olduğu eserler taş işçiliğinde ulaşılan noktayı açıcça gösterir. Taşın kullanım alanlarında olduğu gibi malzemesinde de çeşitliliklerin olduğu görülen mekânda farklı taş cinslerinin de bir arada kullanıldığı görülür. Krallığın bulunduğu coğrafyada volkanik kökenli dağların varlığı havzanın jeomorfolojik yapısının çeşitli kayaç türleri ile şekillenmesine neden olmuştur. Belki de bu yüzdendir ki bu topluluk taş ile şekillenmiş, mimari başta olmak üzere birçok alanda bu materyalden faydalanmıştır. Kuşkusuz kolay bulunabilir olması tek sebep değildir; dayanıklılık ve görsel çekicilikleri ile de taş her daim kullanım görmüştür. 
Bu bağlamda bakıldığında özel bir yapı olduğu öngörülen bu mekâna ait küçük buluntularda kireç taşı, serpantin, volkanik kayaçlar ve yarı değerli taşlar gibi çeşitli taş türleri ile yapılmış heykel/heykelcik, taş kap, taş halka, kakma bezeme ve boncuklar görülmüștür. Salonda ele geçen eserler arasında bu mekâna ait olmadığını düşündüğümüz üzeri kazıma bezemeli kireç taşı parçalar bulunur. Kanatlı tanrı, sfenks ve grifondan oluşan fantastik yaratıklara ait baş, kanat ve gövde kısımları; hayat ağacının dalları ve rozet motifine ait kireç taşları parçalar halinde gelmiştir. Yan yüzlerinde deliklerin olduğu bu kireçtaşı parçalar, Podyumlu Salon'a bitişik konumda yer alan Haldi Tapınağı'nın cellasına ait olmalıdır (Görsel 4). Taş bloklar üzerine oyma tekniğinde işlenen figürlere kakma tekniğinde yerleştirilen kireç taşı bezemeler, Urartu mimari süslemesine yeni bir boyut kazandırmıştır. Bu tip bir uygulama Toprakkale'de de görülür; burada oyma tekniğinde işlenen figürün doldurulması ise kireç taşı ve farklı olarak metal ile gerçekleştirilmiştir. Kurşun akıtma yöntemi ile yerlerine oturtulan bu kireç taşı bezemeler, Ayanis ve Toprakkale örnekleri ile Argişti oğlu Rusa dönemine özgü olarak atfedilmiştir (Barnett, 1950: 43; Curtis, 2012: 431-438). Her ne kadar bu mekânda ele geçmiş olsalar da hem Haldi Tapınağının cellasında bu tip bir uygulamanın yer alması hem de Podyumlu Salon'da bu süslemenin uygulanabileceği bir alanın olmaması sebebiyle bu eser grubunu mekânın dışında tutmak gerekmektedir.

Malzemesinin kireç taşı olduğu bir diğer buluntu grubu heykel/heykelcikler ve buna ait parçalar oluşturur. Yontu sanatı içerisinde değerlendirilebilecek bu eserlerin varlığı hem Ayanis hem de Urartu için oldukça önemlidir (Görsel 5). Çünkü taşa dayalı yontu sanatının örneklerine Urartu'da çok az rastlanılır. Bulunan örneklerin büyük bir çoğunluğu yine Argişti oğlu Rusa dönemine ait yerleşimlerden ele geçmiştir. Urartu sanatında örneklerine az rastlamadığımız bu ünik eserlerden başlıcası, kireç taşından yapılan aslan başıdır (Detaylı bilgi için bkz. Işıklı ve Aras, 2016: 431-444). Ayrıca bu aslan başına oranla daha küçük boyutlarda olan başka bir aslan başı, koç başı (Detaylı bilgi için bkz. Işıklı ve Özdemir, 2019: 502-503) ve insan başlı figürinden oluşan üç eser daha bulunur. Üç boyutlu tam plastik eser olarak değerlendirilecek bu eserlerin tasvir edilişleri oldukça başarılıdır. Detaylarına inildiğinde de bu eserlerin stil açısından birer etkileşim ürünü oldukları da dikkati çeker5. Bu heykel örneklerin yanı sıra bir de kireç taşından yapılmış göz taşları ele geçirilmiştir ki bu örneklerin benzerlerine tapınak alanında da rastlandığı tespit edilmiştir. Heykelciklere ya da aslan başlı bronz kalkan gibi örneklere ait olduğu düşünülen bu göz taşlarının (Sağlamtimur vd., 2001: 224-225), Tapınak Alanı'nda ele geçen taşlar ile birlikte değerlendirildiğinde sayılarının oldukça fazla olduğu görülür. Bu durum kazılar sırasında ele geçen heykel/heykelciklerden daha fazla örneğin olabileceğini de akıllara getirmiştir.

Bir diğer grubu, Haldi Tapınağı ve Tapınak Alanı'nın duvarlarını süslediği düşünülen kakma taş halkalar oluşturmaktadır. Daha önce tapınak alanından başka hiçbir yerde ele geçmeyen kireç taşı ve serpantinden yapılan bu iç içe geçmiş taş halkalar, Podyumlu Salon'da da ele geçmiştir (Görsel 6). Mekânın farklı alanlarında ve seviyelerinde karşımıza çıkabilen mozaiklerin, bezemeli podyumun olduğu kısımlarda yoğunlaştığı gözlenmiştir. Alanın güney duvarına yaslı konumdaki podyumun üzerinde tek sıra halinde in situ olarak ele geçen örneklerin dışında, çapları 0.8 cm'den 4.4 cm'ye kadar değişen hem bronz çivili hem de çivisiz taş halka ele geçmiştir. Hem Tapınak Alanı'nda hem de Podyumlu Salon'daki ele geçen örneklerine bakıldığında bu taş halkaların her iki podyumda ve mekânın duvarlarında süsleme ögesi olarak kullanıldığı düşünülmektedir. Ancak şu an için Podyumlu Salon'da ele geçen taş halkaların podyumun süslemesi dışında, başka bir amaçla (duvar süslemesi olarak) kullanıldığına dair bir veriye rastlanılmamıștır. Bununla birlikte taş halkaların zemin süslemesi olarak kullanıldığına dair örneklere Toprakkale, Bastam ve Armavir Blur yerleşimlerinde rastlamaktayız (Dan, 2015: 55-58).

\footnotetext{
${ }^{5}$ Belirtilen eserlerle ilgili detaylı yayın çalışması gerçekleștirildiğinden burada detaylı olarak değinilmeyecektir.
} 
Taş halkaların yapımında kullanılan serpantin ile aynı malzemeye sahip olduğu düşünülen bezemeli taş kaplarda bir diğer önemli buluntu grubunu olușturur (Görsel 7). Ayanis'e özgü olduğu bilinen bu taş kapların (Çilingiroğlu, 1994: 68-76; 1997: 183-195; Sağlamtimur, 2009: 565-579) tapınaktan başka bir yer olarak Podyumlu Salon'da çıktığı görülmüştür. Podyumlu Salon'dan ele geçen 10 adet taş kap örneğine bakıldığında, keskin bir kalem ve burgu ile işlenen geometrik ve bitki bezemelerinin bulunduğu, ancak Tapınak Alanı'nda ele geçenler gibi hayvan motifli taş kapların olmadığı dikkati çekmektedir. Geometrik bezemeler arasında daireler, baklava biçimliler ve zigzaglar görülürken, bitki bezeme olarak tomurcuklar, rozetler ve çiçekler kullanılmıştır. Küçük boyutlu olan bu kaplar daha öncede belirttiğimiz gibi Ayanis'e özgüdür bu nedenle benzerleri bulunmamaktadır. Ancak stilistik ve teknik açıdan Ayanis'tekiler ile benzerlikleri bulunmasa da betimli taş kap örneklerine, Argişti oğlu Rusa'nın diğer kentleri olan Karmir Blur ve Toprakkale'de de rastlamak mümkündür.

Taş buluntuların bir diğer alt grubu taş boncuklardır (Görsel 8). Daha önce sadece Tapınak Alanı'nda ele geçen taş boncukların örneklerine, Podyumlu Salon'da da rastlanmıştır. Podyumun bulunduğu salon ve salonun güneyine kalan küçük odada, toplamda 84 adet boncuk ele geçirilmiştir. Yapımında yarı değerli taşların kullanıldığı boncuklarda akik-sardoniks, karnelyen-sard, dumanlı kuvars, kireç taşı, kum taşı gibi taş türleri kullanılmıştır. İnce işçilikleri ile dikkat çeken çok farklı formlarda işlenen bu boncukların en yaygın olanı ise küre şeklinde olanlardır. Bunun yanı sıra az sayıda da olsa elips şeklinde boncuklara da rastlanılır. Bu formda boncukların bazıların da delik kısmına doğru altın kaplama bulunduğu da gözlenmiştir. Tapınak Kompleksi ile ilişkilendirilen mekânlarda ele geçen bu taş boncukların takıdan ziyade bu mekânlarda yürütülen ritüellerin birer parçası olan armağanlar olduğunu düşünmek yanlış olmayacaktır.

$\mathrm{Bu}$ örnekler dışında işlevi hususunda hala belirsizliklerin olduğu birçok taş eser bulunmaktadır. Bu eserlerden 6'sı bezeme tekniği ve motifler açısından taş kaplara oldukça benzeyen ancak form açısından farklılıkların olduğu, taht parçası olabileceği düşünülen taş eserlerdir (Görsel 3). Toprakkale'den ele geçen bronz taht parçalarına oldukça benzeyen bu taş örneklerde delikler olması, bu örneklerin birbirine geçen, eklentili parçalar olduğu fikrini kuvvetlendirmektedir. Ayrıca bu mekânda böylesine bir kurguyu akla getirecek başka bir sebep daha vardır. Mekânda yer alan podyumun üzerinde fark edilen yuvarlak izler, podyumun üzerinde yer alan bir taht veya kaidenin varlığını akla getirmektedir. Yine işlevi hususunda belirsizliğin bulunduğu üzerinde geometrik motiflerin yer aldığı disk şeklinde (?) taş objelerde bulunmaktadır ki, belki de bunlarda kaide ayakları gibi bir işlev görmektedir. Bu eserlerin dışında da işlevselliği çözülememiş birçok eser bulunmaktadır. Bu örneklerin form vermemesi ve tam olarak ele geçmemesi, bu buluntuların değerlendirmesinde sıkıntılara yol açmaktadır.

Görüldüğü üzere Podyumlu Salon, materyalini taşın oluşturduğu zengin bir koleksiyona sahiptir. Taşın yanı sıra bunu metalde de sağladığını söylemek yanlış olmayacaktır. Üretim malzemelerine göre bu eserler altın, bronz ve demir olmak üzere üç farklı türde karşımıza çıkmıştır. Bu buluntu grupları arasında altın objeler önemli bir yer teşkil etmektedir. Podyumlu Salon'un zengin ve önemli koleksiyonlardan birini oluşturan bu altın objeler; rozetlerden levhalara, altın tanelerinden, çivilere ve sfenkse kadar çeşitlilik göstermektedir (Görsel 9). Bu çeşitlilik içerisinde en dikkat çeken eserlerden biri de altın rozetlerdir. Çapları 0,5 cm' den 2,6 cm'ye kadar değişen bu rozetler, varak kaplama tekniğiyle işlenerek bronz rozetlere aplike olarak kullanılmıştır. Altın kaplı bu bronz rozetler, alanın farklı bölgelerinde tespit edilmesine rağmen yoğun olarak salonun güneyinde yer alan odadan ele geçmiştir. Arka odanın mimarisinde izlerine rastladığımız ahşap düzenlemenin (duvarı bir bordür gibi bölen kısım) yakınlarında, çok sayıda in situ durumda, altın kaplı bronz rozetler ele geçmiştir. Bu in situ buluntular, arka odanın düzenlemesi yönünde öne sürülen görüşü destekler niteliktedir. Bu tip süsleme tekniğinin benzerinin sitadel içerisinde yer alan Evsel 
Mekânlar'da da uygulandığı görülür6. Söz konusu rozetlerin süsleme öğesi olarak farklı versiyonunu Ayanis dışındaki merkezlerde de görmekteyiz. Özellikle Altıntepe'de yer alan Apadana'nın duvar resimlerindeki sahnelerin sınırlandırılmasında doldurma motifi olarak kullanılmıştır (Özgüç, 1966: Pl III). Rozetler, mimari öğeler dışında plastik eserlerde de karşımıza çıkmaktadır. Kef Kalesi'nin ünlü Teişeba kabartmasında giysisi (Loon, 1966: 72, Res.9) ile Toprakkale Haldi Tapınağı'nda ele geçen kabartmanın giysisi (Wartke, 1990: 42-43 Taf. 1-2) üzerinde rozetlerin süsleme öğesi olarak kullanıldığı görülmektedir. Podyumlu Salon'dan ele geçen ve aplike rozetlerden farklı olarak, arka kısmında ip halkaları bulunan rozetler, altınların kıyafetlerde süsleme elemanı olarak kullanıldı̆̆ını kanıtlar niteliktedir.

Podyumlu Salon'un altın eserler grubundan bir diğerini sfenks oluşturmaktadır. İnsan başlı aslan gövdeli ve kanatlı olarak betimlenen eser, $4 \mathrm{~cm}$ uzunluğa $3,4 \mathrm{~cm}$ yüksekliğe ve $0,3 \mathrm{~cm}$ kalınlığa sahiptir. Varak kaplama tekniğinde yapılmış eserin üzerinde aplike edilmek için kullanılan çivilerin, bronz izleri yer almaktadır. Ayanis sfenksi olarak anılan betimin benzerlerini cellada yer alan andezit bloklarda, cella içerisinde yer alan podyum üzerinde ve eserin tespit edildiği salondaki podyum üzerinde görmek mümkündür. Urartu sanatında çok sık karşımıza çıkan sfenks tasvirini, Ayanis dışındaki merkezlerde de görmemiz mümkündür. Toprakkale'den ele geçen bronz şamdan ayağı üzerinde yer alan sfenks tasviri (Loon, 1966: Plate XIV-XIX) ile Altıntepe duvar resimlerinde (Özgüç, 1966: Res. 27) yer alan sfenks tasvirleri, sfenks betimlemelerinin Urartu sanatındaki çeşitliliğini göstermektedir. Podyumlu Salon'da yoğun olarak tespit edilen diğer altın objeler ise altın taneleri ve altın plakalardır. Küçük küre şeklinde olan altın taneleri, podyum üzerinde ele geçmiştir. Çapları 0,12 $\mathrm{cm}$ ve $0,28 \mathrm{~cm}$ arasında değişen bu tanelerin tekstil parçasıyla birlikte ele geçmesi, bunların tekstile iliştirilen aplikler olabileceğini düşündürmüștür. Podyum üzerinde ele geçen diğer bir eser grubu altın plakalardır. Altın taneleriyle birlikte in situ olarak ele geçen bu plakalar, kabartma tekniğinde geometrik motiflerle süslüdür.

Podyumlu Salon'dan ele geçen diğer bir buluntu grubu ise bronz eserlerdir. Bronz eserler içerisinde rozet, ok uçları, çivi, yaprak formlu bronz obje ve çok sayıda amorf niteliğinde bronz parçalar yer alır (Görsel 10). Bu eserler içerisinde en dikkat çekici olanları kuşkusuz ok uçları ve yaprak formlu bronz objedir. Köşeleri yuvarlatılmış ve uç kısma doğru daralan bir forma sahip olan bronz objenin üzerinde yer alan altın kalıntıları, bu eserinde bronz rozetler gibi altın varak ile kaplı olduğunu düşündürmüştür. Bronzdan yapılmış ok uçlarının yanı sıra demirden yapılmış ok uçları ele geçmiştir. İki farklı tipte ok ucu ve bir adet kılıçla da Podyumlu Salon'un metal eserleri tamamlanmıştır (Görsel 11).

\section{Sonuç}

Farklı mimarisi, anıtsal yapısı ve içerisinde barındırdığı çok çeşitli buluntularla bu mekân, Urartu mimarisi için şu an için tektir. İç düzenlemesinden mimari formuna ve hatta işlevine kadar birçok sorunsalı beraberinde getiren bu yapının dinî ve krali aktivitelerin yürütüldüğü özel bir alan olduğu ise kesindir. Yapı içerisindeki kontekstten ele geçen zengin buluntu topluluğu da özellikle mekânın iç düzenlemesinin ne kadar görkemli olduğunu yansıtır. Ancak bu zengin buluntu grubunun büyük bir bölümü, Podyumlu Solun olarak nitelendirilen alanın hemen bitişiğinde yer alan Tapınak Cellası'na ait eserlerdir. Dolayısıyla sadece buluntu gruplarından yola çıkılarak mekânın işlevine dair net iddialarda bulunmak şu an için erkendir. Özellikle metal ve taşa dayalı materyalin yoğunluk oluşturduğu bu alanda ele geçen eserlerin büyük bir bölümü Urartu sanatında ilk kez karşımıza çıkan ünik eserlerdir. Urartu'nun sonuna doğru ilk kez karşımıza çıkan bu örnekler Urartular'ın özellikle tunç ve taş sanatındaki zanaatkârlıklarını da açıkça gösteren kanıtlardır. Metal eserler içerisinde kılıç, ok ucu, çivi, rozet ve yaprak formlu bronz obje önemli bir yer tutarken, taş eserler de ise kireç

${ }^{6}$ Merasim koridoru olarak adlandırılan mekânın, kuzey ve güney duvarı önünde çok sayıda altın kaplı bronz rozetlerin yer aldığı ve bunların duvarlara aplik edildiğinden bahsedilmektedir. Detaylı bilgi için bkz. (Batmaz, 2012: 41-42) . 
taşı aslan başı, koç başı, taş boncuk, taş halka, taş kap, taht parçası (?) gibi objeler çeşitlilik gösterir. Görüldüğü üzere Podyumlu Salon özellikle taş ve metal eser açısından oldukça zengin bir buluntu topluluğu sunmuştur.

\section{Yazar Katkı Oranları}

Çalışmaya 1.Yazar: \%50, 2. Yazar: \%30, 3. Yazar: \%20 oranında katkıda bulunmuştur.

\section{Kaynakça}

Barnett, R.D. (1950). The Excavations of the British Museum at Toprak Kale, near Van, Iraq 12: 1-43. Batmaz, A. (2012). Ayanis Kalesi' nden Hayat Ağacı İnancına İlişkin Yeni Bulgular. Arkeoloji ve Sanat, 141, 39-50.

Çilingiroğlu, A. (1994). Decorated Stone Vessels From the Urartian Fortress of Ayanis. Tel Aviv, 21, 68-76.

Çilingiroğlu, A. (1997). Urartu Krallı̆̆ı Tarihi ve Sanatı. İzmir.

Çilingiroğlu, A. (2007). Urartulu Argişti Oğlu Kral Rusa: Bir Başarı Öyküsü. Tüba-Ar, X, 73-89.

Çilingiroğlu, A., ve Işıklı, M. (2014). 25. Yılında Ayanis Kalesi Kazıları-Dün, Bugün ve Gelecek. İçinde H. Kasapoğlu ve M. A. Yılmaz (Ed.), Anadolu'nun Zirvesinde Türk Arkeolojisinin 40. Yılı. Ankara: Bilgin Kültür Sanat Yayınları.

Çilingiroğlu, A., ve Salvini, M. (2001). Historical Background of Ayanis. İçinde A. Çilingiroğlu ve M. Salvini (Ed.), Ayanis I (Ten Year's Excavation at Rusahinili Eiduru-kai 1989-1998) (ss. 15-67). Roma: CNR Instituto Per Gli Studi Micerei Ed Egeo-Anatolici.

Cohen A. - Kangas, S. E. (2017). Inside an Ancient Assyrian Palace. University Press of New England. London.

Curtis, J. (2012). Assyrian and Urartian Meralwork: Independence or Interdependence ?, In:. S. Kroll - C. Gruber - U. Hellwag - M. Roaf - P. Zimansky (eds.), Biainili-Urartu, The Proceedings of the Symposium Held in Munich 12-14 October 2007 (Münih 2012) 427-443.

Dan, R. (2015). Circles in Stone: Urartian Decorative Inlay Stone. ARAMAZD, IX(2), 55-66.

Işıklı, M., ve Aras, O. (2016). Ayanis Aslanı. İçinde E. Dündar, vd. (Ed.), Havva İşkan'a Armağan. Lykiarkhissa Festschrift für Havva İşkan (ss. 431-444). istanbul: Ege Yayınları.

Ișıklı, M., ve Özdemir, M. A. (2019). Ayanis Kalesinden Ünik Bir Eser: Ayanis Koçu. İçinde V. Keleş, vd. (Ed.), Cevat Başaran'a 60. Yaş Armağanı, Essays for Cevat Başaran's 60th Birthday Occasion (ss. 499-510). Ankara: Bilgin Kültür Sanat Yayınları.

Loon, M. N. v. (1966). Urartian Art. Its Distinctive Traits in the Light of New Excavations. İstanbul: Nederlands Historisch-Archaeologisch Instituut.

Özgüç, T. (1966). Altıntepe Mimarlık Anıtları ve Duvar Resimleri, Architectural Monoments and Wall Paintings. Ankara: Türk Tarih Kurumu.

Özgüç, T. (1969). Altıntepe II Mezarlar, Depo Binası ve Fildişi Eserler, Tombs, Storehouse and Ivories , Türk Tarih Kurumu Yayınlarından - V. Seri, No.27. Ankara.

Sağlamtimur, H. (2009). Urartu'da Fildişi Oymacılığı, Ayanis Taş Kapları ve Haldi Tapınağı. İçinde H. Sağlamtimur, vd. (Ed.), Altan Çilingiroğlu'na Armağan Yukarı Denizin Kıyısında Urartu Krallığı'na Adanmış Bir Hayat. Studies in Honour of Altan Çilingiroğlu A Life Dedicated to Urartu on the Shores of the Upper Sea (ss. 565-579). İstanbul: Arkeoloji ve Sanat Yayınları.

Sağlamtimur, H., Kozbe, G., ve Çevik, Ö. (2001). Small Finds İçinde A. Çilingiroğlu ve M. Salvini (Ed.), Ayanis I: Ten Year's Excavation at Rusahinili Eiduru-kai 1989-1998 (ss. 251-320). Roma: CNR Instituto Per Gli Studi Micerei Ed Egeo-Anatolici.

Salvini, M. (2006). Urartu Tarihi ve Kültürü. İstanbul: Arkeoloji ve Sanat Yayınları.

Seidl, U. (1994). Der Thron von Toprakkale. Ein neuer Rekonstruktionsversch. AMI 27: 67-84.

Wartke, R. B. (1990). Toprakkale. Untersuchungen zu den Metalobjekten im vorderasiatischen Museum zu Berlin. Berlin.

\section{Extended Abstract}

In the mid-9th century BC, the Urartian State emerged as the dominant political power in the mountainous Eastern Anatolia and its nearby lands. They ruled over a wide geographic area from the Euphrates River in the west to Lake Urmiye in the southeast, from Erzurum-Kars plateau in the north to Lake Sevan in the northeast. The Urartian kings 
laid the foundations of the state around Lake Van and declared Tuspa as their capital in a short time. Ayanis Castle is one of the five big castles built by Argiști's son Rusa during his reign. In the recent excavations of Ayanis Castle, an architectural structure that we have not seen in the Urartian culture before is noteworthy. This unprecedented structure is located in just west to the temple courtyard, which we call as the "Podium Hall", has mostly rectangular plan and consists of a large main room and a smaller back room. The main room, which forms the center of the hall, is $22 \times 8 \mathrm{~m}$, while the back room, where a passage is allowed from the hall, is a small room measuring 4,5x8 $\mathrm{m}$. Two different materials were used as flooring on the ground of the hall, which covers an area of approximately $250 \mathrm{~m}^{2}$. The $15 \mathrm{~m}^{2}$ area located in the southwest corner of the space, which is thought to serve a different purpose, was laid with onyx blocks, while the remaining part of the floor was laid with mudbrick blocks. This area between the podium and the west wall is covered with 49 onyx blocks of $50 \times 50 \mathrm{~cm}$ in $5 \times 10$ order. Most of the walls surrounding the place have solidly survived to the present day. The mudbrick walls, 2 to $3 \mathrm{~m}$ in height, were plastered like the walls of the temple courtyard and decorated with Urartian blue paint.

Undoubtedly, the most important and striking architectural element of this monumental building is the onyx podium located in the southern part of the hall, similar to what we have seen in the cella before. This podium, which reveals the splendor of Urartian art, has dimensions of $2.50 \times 2.60 \mathrm{~m}$ and a height of $76 \mathrm{~cm}$. It has eight blocks in 22-4 order on the upper part. It consists of a total of fifteen onyx blocks, seven blocks on the side faces. The platform is decorated with very elegant motifs in the incised decoration technique.

Mosaics with diameters of $35 \mathrm{~mm}$ and attached to the marble with nails were found along the borders of the podium. While these mosaics are observed in a single row on the upper and side borders of the platform, they are lined up in double rows in the lower part of the front. A total of 41 of these mosaics were recovered intact and in situ. According to the calculations, there should be at least 350 mosaics on the podium. In addition to these, many gold plates were found on and around the podium. Based on these gold plates, it can be suggested that at least part of the podium was decorated with gold plates.

Apart from this, the most striking element found on the podium is the 4 circular traces on the ornamented motifs. While 3 of these 4 traces with a diameter of $7 \mathrm{~cm}$ are clearly visible, the traces located in the northeast part of the podium are not clear. As can be seen from the traces, there was a rectangular object (probably a furniture piece) on the podium with a width of $60 \mathrm{~cm}$ and a length of $30 \mathrm{~cm}$. These traces are important in terms of the clues they provide about the usage purposes of the podiums.

The Podium Hall has brought a special collection to the Urartian cultural inventory not only with its architecture but also with its variety of finds in quality and quantity. Especially in this area where metal and stone-based materials are common, most of the works unearthed are unique works that appear for the first time in the Urartian art. These examples, which we encounter for the first time towards the end of Urartu, are pieces of evidence that clearly show the craftsmanship of the Urartians, especially in bronze and stone arts. While swords, arrowheads, nails, rosettes, and leaf shaped bronze objects occupy an important place among metal works, objects such as limestone lion head, ram head, stone bead, stone ring, stone vessel, and throne pieces are among the samples in stone works.

Among the groups of works based on these two materials, the most important one is stone works with their flawless craftsmanship. Monumental architectural understanding based on stone, especially in this period and in this place, clearly show the point Urartians reached in stone workmanship. It is seen that different stone types are used together in the place, which is seen to be diverse in the material as well as in the usage areas of the stone. The existence of mountains of volcanic origin where the kingdom was located caused the geomorphological structure of the basin to be shaped by various rock types. Perhaps, this may be the reason why the community opted for stone and benefited from this material in many areas, especially in architecture. Of course, the easy availability of stone is not the only reason as it has always been used with its durability and visual appeal.

As it can be seen, the Podium Hall has a rich collection consisting of the stone materials. It would not be wrong to say that it is rich in metal too. According to the production materials, these artifacts come in three different types: gold, bronze, and iron. Among these groups of finds, gold objects occupy an important place. These gold objects, which constitute one of the rich and significant collections of the Podium Hall range from rosettes to plaques, gold grains, spikes and sphinxes. Another group of finds recovered from the Podium Hall is bronze works. Bronze works include rosettes, arrowheads, nails, leaf-shaped bronze objects, and many amorphous bronze pieces. Among these works, the most striking ones are undoubtedly the arrowheads and leaf-shaped bronze objects. The gold remains on the bronze object, which have rounded corners and a form that narrows towards the end, point out that this workpiece was also covered with gold leaf like bronze rosettes. 


\section{Görseller}

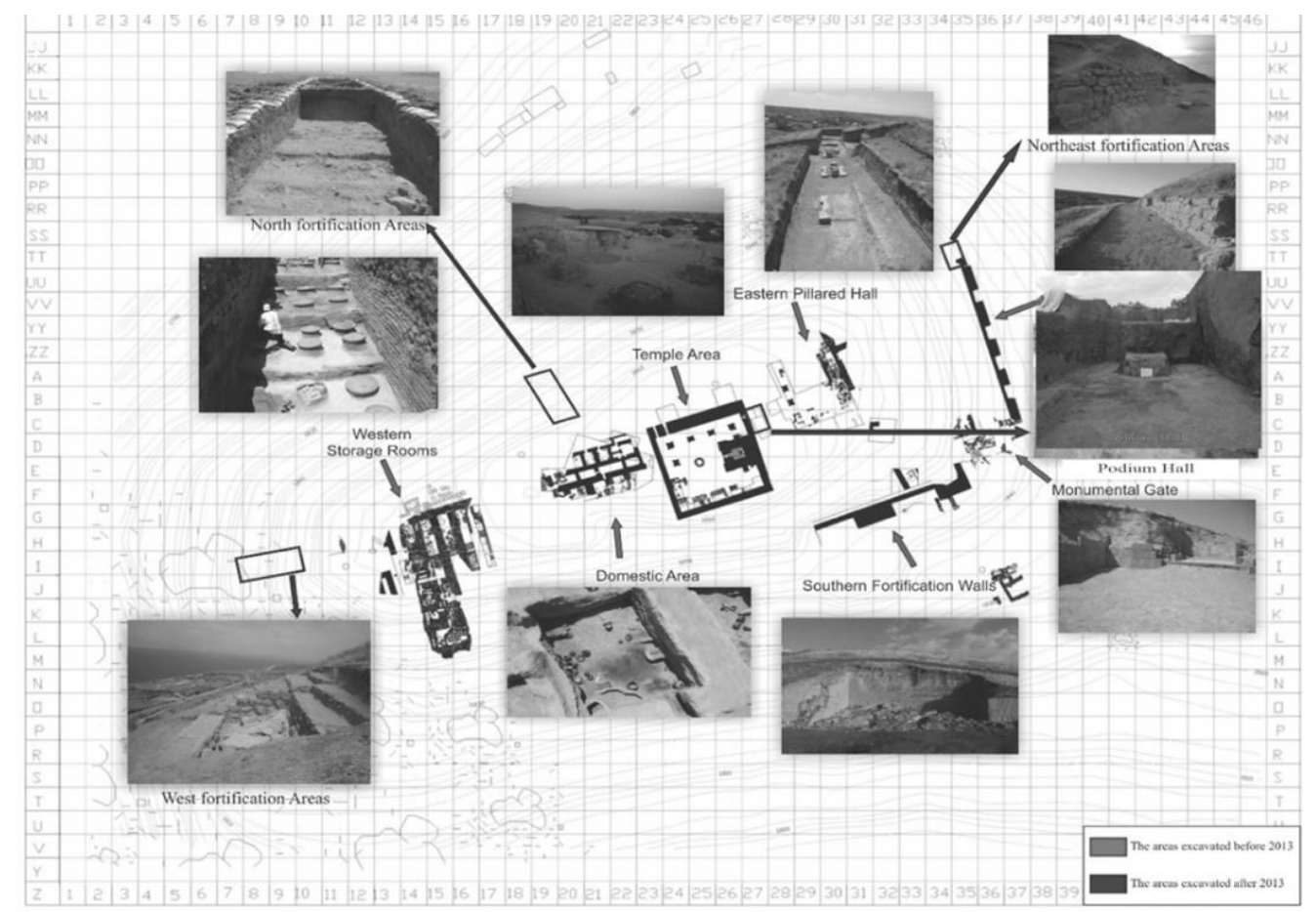

Görsel 1: Ayanis Kenti'nde Kazısı Yapılan Alanlar.

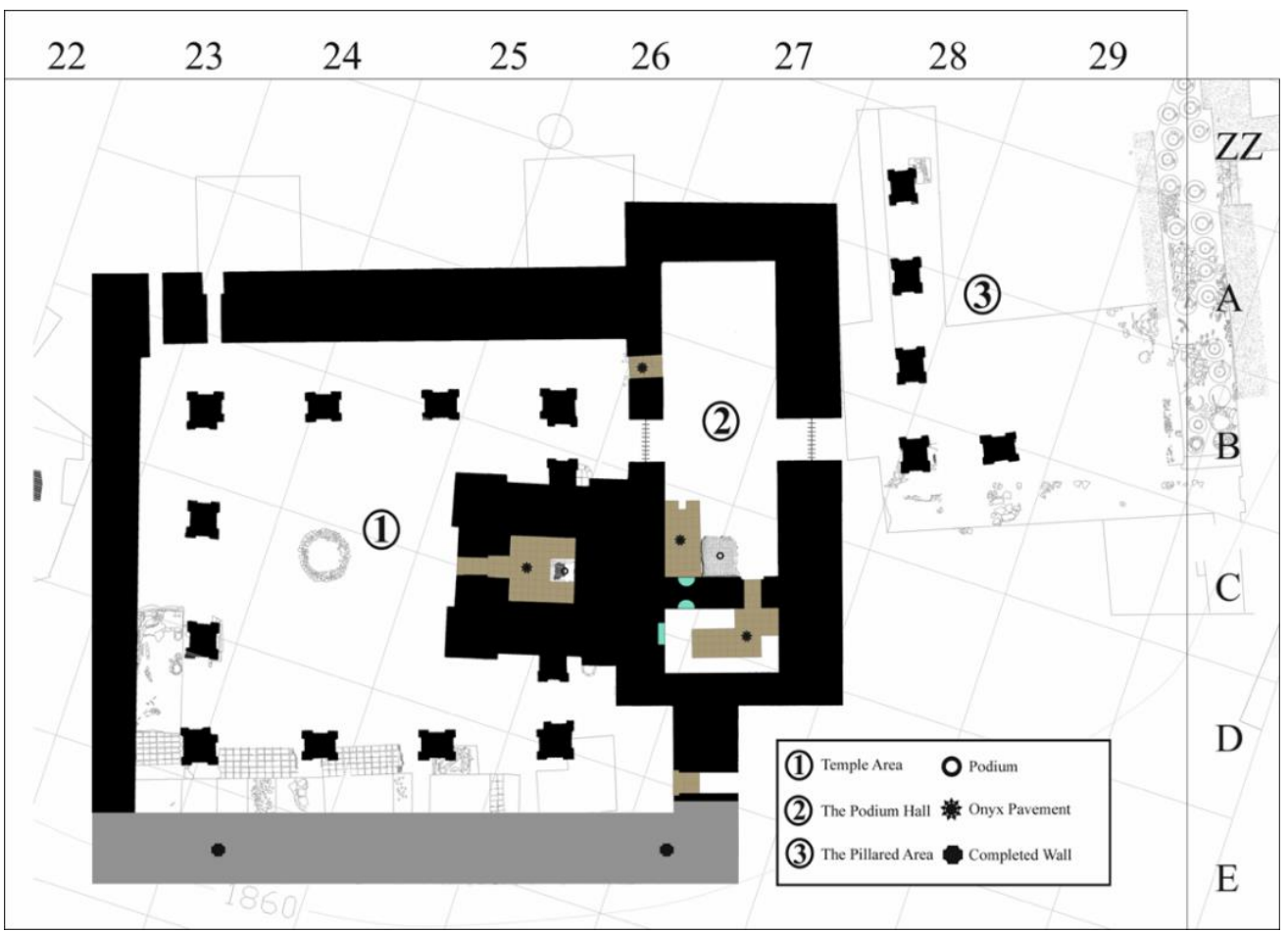

Görsel 2: Tapınak Alanı, Podyumlu Salon ve Payeli Salonu Gösterir Harita. 

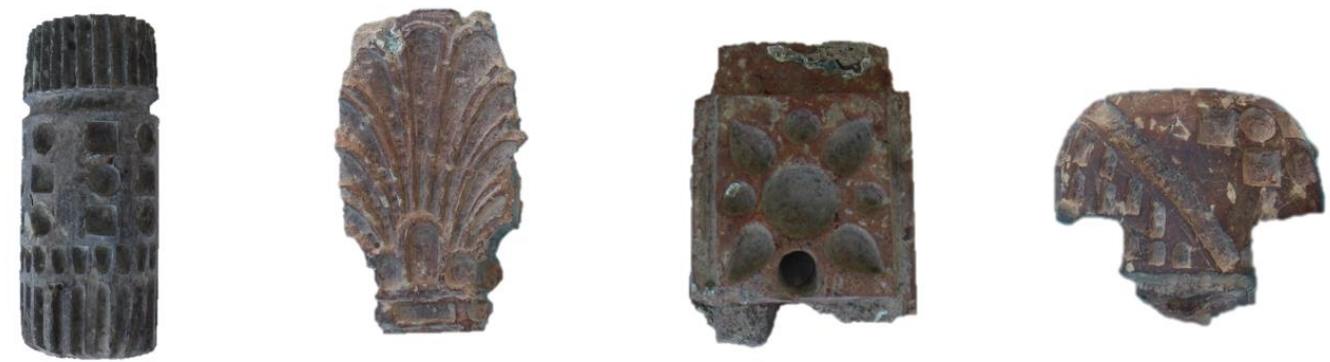

Görsel 3: Taht Parçası Olarak Düşünülen Buluntulardan Örnekler.
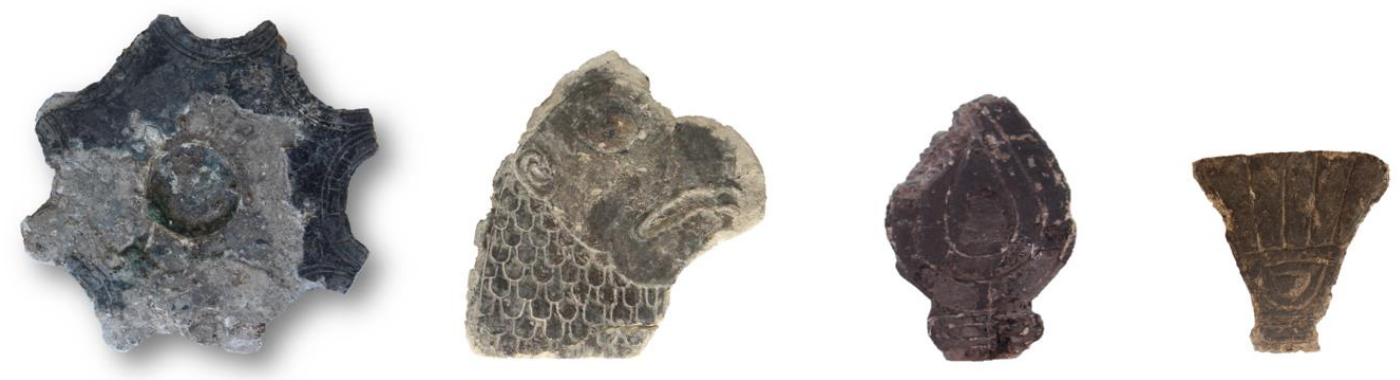

Görsel 4: Bezemeli Kireç Taşı Buluntulardan Örnekler.
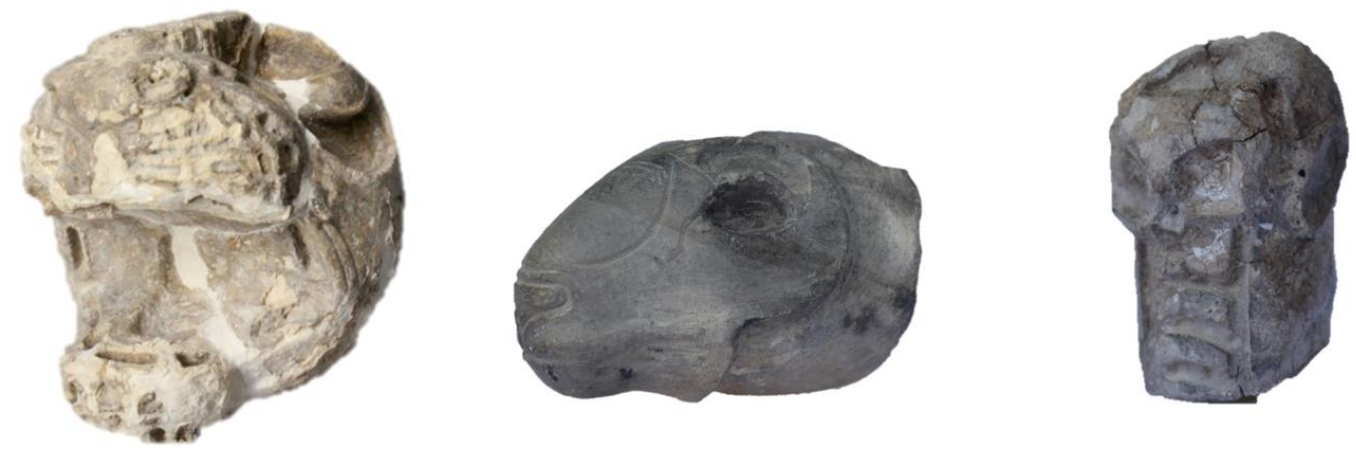

Görsel 5: Aslan, Koç ve İnsan Başlı Buluntular. 

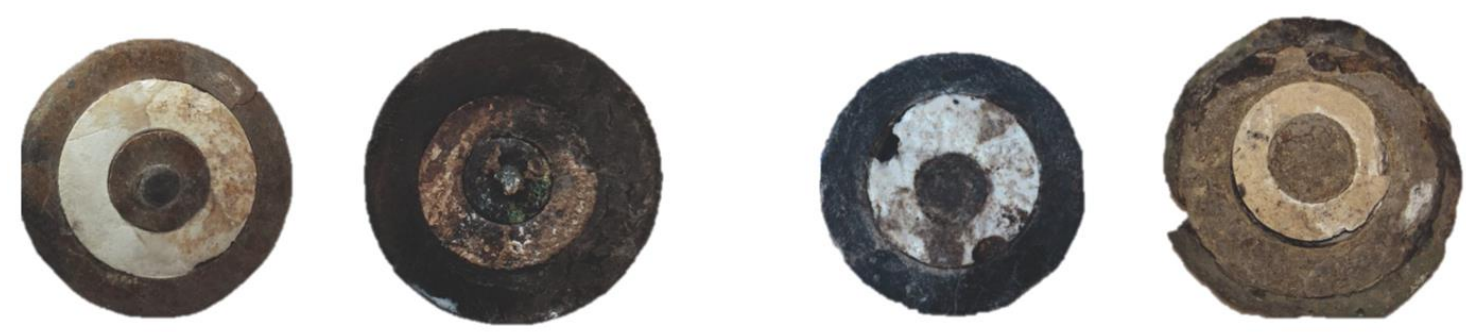

Görsel 6: Kakma Taş Halka Buluntulardan Örnekler.
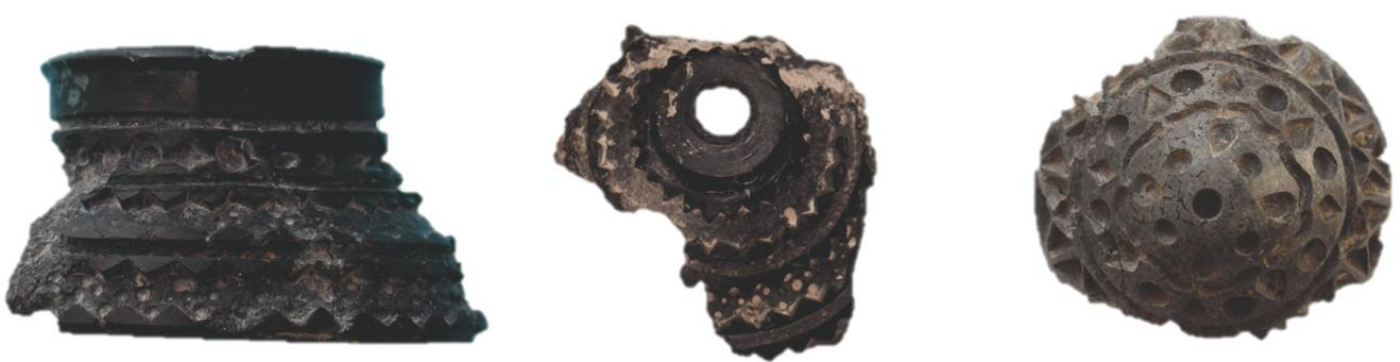

Görsel 7: Taş Kap Buluntulardan Örnekler.
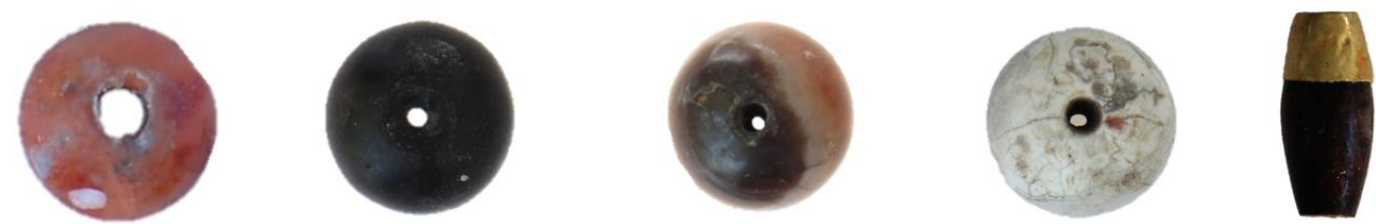

Görsel 8: Boncuk Buluntulardan Örnekler. 


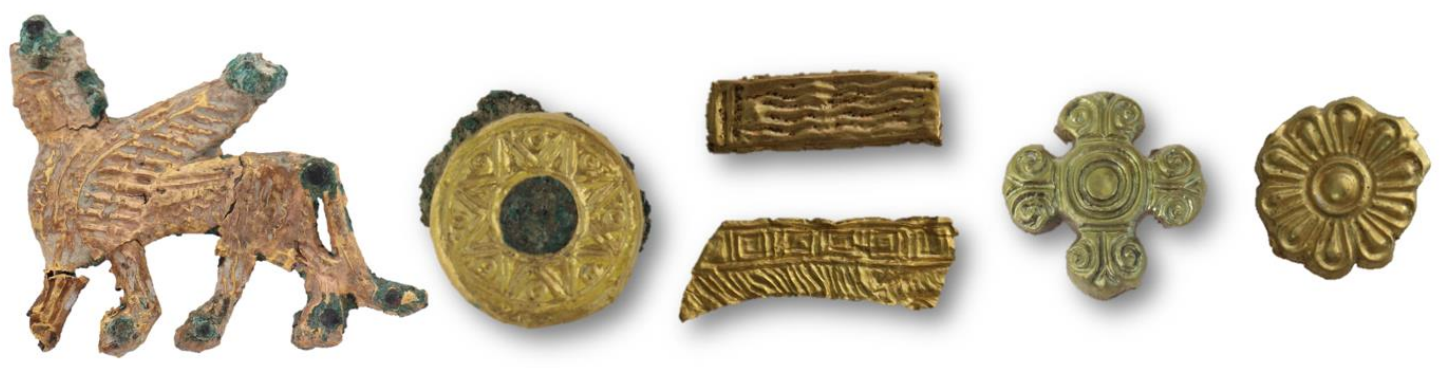

Görsel 9: Altın Buluntulardan Örnekler.

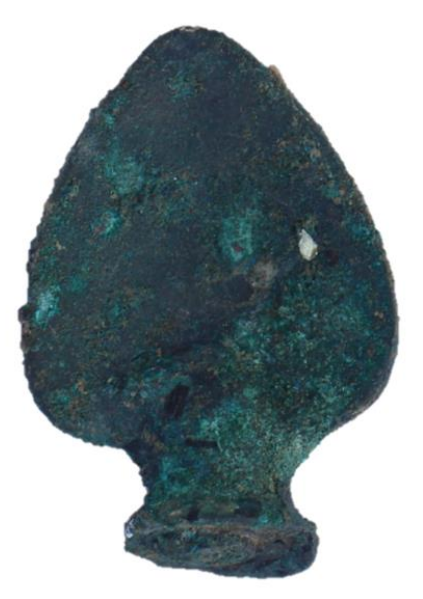

Görsel 10: Bronz Buluntu Örneği.

Görsel 11: Demir Buluntu Örneği. 